\title{
Academic Performance, School Desertion And Emotional Paradigm In University Students
}

Emma Rosa Cruz Sosa, Benemérita Universidad Autónoma De Puebla. México Laura Gática Barrientos, Benemérita Universidad Autónoma De Puebla. México Patricia Eugenia García Castro, Benemérita Universidad Autónoma De Puebla. México Jesús Hernández García, Benemérita Universidad Autónoma De Puebla. México

\begin{abstract}
The present work aims to describe academic performance, school desertion and the emotional paradigm of the university students of the accounting school of the Benemérita Universidad Autónoma de Puebla (FCPBUAP). We have found that low academic performance is related to students' economic deficiency, which affects their concentration on their studies, as well as the realization of works and tasks assigned. Schedules offered by university cause conflict with their paid work schedules, provoking difficulty in planning and organizing their scholastic and labor activities. The low wages of the students and their parents cover neither personal nor academic needs (books, materials, computer). Other factors which affect academic performance and school desertion are: pregnancy, depression, family disintegration, stress, distrust, lack of communication, addiction, domestic violence, lack of respect, lack of communication, etc. therefore it is very common for students to be sad, unmotivated, frustrated, or to feel like leaving college; In addition, many of them did not choose their career by self-conviction, but by influence, family tradition or fashion. Furthermore, the lack of understanding of educational authorities discourages students.
\end{abstract}

Keywords: Emotions, academic performance, desertion

\section{INTRODUCTION}

$\mathcal{G}$ n today's context of globalization, world economies cannot and must not remain on the sidelines of the technological, ideological and social changes that enable its people to have equal opportunities to compete with their international peers, that is why an analysis was made about academic performance and school desertion in the new global educational context, as well as the emotional impact of the latter. In the present time, most Mexican families have been affected by these multifaceted changes.

The FCPBUAP is a public university, where most of the student population is poor, so in some cases, students have to work in order to continue their studies and even to support their family.

México and particularly Puebla, is inhabited by a conservative population, and while modernity elsewhere on the planet is advancing rapidly, in Puebla, like in any good provincial society, it progresses slowly. it is therefore not well seen for a young woman to get pregnant without being previously married. The state law in Puebla prohibits abortion, this, often added to strong morals which cause lack of communication and problems for dysfunctional families, seriously increases problems for young people.

This research aims to determine situations that students of the FCPBUAP face because of their age and the environment in which they develop, such as: family, economic, emotional, social and cultural aspects, which affect academic performance, provoking temporary or definitive desertion. 


\section{LITERARY REVIEW}

The academic or school performance is the level of knowledge and development of abilities and skills that an individual has at a certain level of education, and which generally in México is assessed by means of numeric assignment on a scale from 0 to 10 . Students pass with a numerical grade equal or higher than 6 . Although not in all cases, there are youngsters who get lower grades than 6. Perhaps, it happens as a result of the adjustment, since they are in a process of adaptation where they will have new classmates, a greater number of teachers and more courses to study. Therefore they may be vulnerable to decreasing their academic performance, suffering psychological troubles and starting to behave in a risky manner (Ramírez, 2004).

In the colleges, transmitting knowledge to the next generation may be one of the most gratifying and challenging activities of this profession. Two current paradigms have influenced research on teaching and learning.

1) The omen-process-product model that includes three phases: presaging variables (student's characters and the learning environment), process of variables (self-adjusted focuses on the student, which means studying habits in order to learn and study) and variables of product (learning results of students) and 2) interaction paradigm called aptitude-treatment. Aptitude is defined as any variable hypothesized measurable individual that is necessary for the achievement of the objective. The word treatment serves to cover variables conforming the learning environment. And the interaction occurs when a learning situation has an effect on a type of individual and a different effect on another one. (De la Fuente J; Cardelle M. 2009)

According to research, prior academic achievements are the most important variable in the explanation of the first academic year's performance of the accounting students of an Irish university. This finding has serious consequences for the universities' admission policies, at least with regard to accounting programs. However, today, as higher education institutions are struggling for wider access, it is necessary to pay attention to ensure that any related initiative does not give rise to less able students being accepted onto programs which are unsuitable. Furthermore if students have not developed their full academic potential THEY may need additional support at the beginning of their university studies that allows them to develop the abilities and skills needed to succeed. That support may include: peer counseling, a personal tutor system and tutors assigned to small groups. Understanding the factors associated with success and academic failure is particularly important to achieve greater participation in higher education,

Since the intention of policy initiatives is not simply to encourage students to begin higher education studies, but to successfully complete them. It is clear that most of educators' information concerning the knowledge of the factors associated with success or academic failure, can enhance the ability to support students and provide advice to potential candidates. These students chose an accounting degree since those are their career aspirations, and besides they enjoyed the subject when they were in high school. In the same way, students expect the higher instruction gotten in the college to contribute to their career via the development of skills and appropriate competencies. Similarly, students have confidence in their preparation for higher education and consider that they will carry out their further studies well. (Byrne, 2008)

A correlation between the previous knowledge of accounting and performance of students in financial accounting and management accounting modules should help dispel the students' doubts concerning their ability to do well in these subjects. Advisors can be sure of helping students by telling them that if they do not study accounting in college, they will be at a disadvantage should they decide to enroll on an accounting degree. Moreover, these findings also suggest that the students who have studied accounting in college are more successful than other students in these modules.

In addition, the outcomes can help identify students at risk of school failure. The results show that students with lower academic ability, no prior knowledge of accounting, a lack of confidence in their skills and abilities and no clear objectives of their career, perform poorly in the first year of their degree. (Byrne 2008)

Academic performance problems with low grades or desertion are significant predictors of health problems, such as the consumption of drugs, depression, early pregnancy, parenthood, abortion and other social difficulties, 
such as unemployment and crime, resulting in increased social spending paired with a low quality of life. In accordance with the National Institute of Statistics, Geography and Informatics (INEGI), the rate of failure in Mexico was 22.8 per cent and the rate of desertion was 6.4 per cent in 1996-1997. The conduct-problem theory commonly supposed that the relationships between peers can have a negative influence on academic performance (Ramírez, 2004).

University student desertion is a problem is currently particularly serious in National, Latin American, European and North American University institutions, both public and private. For example, in some countries, such as Spain, United States, France and Austria the rate of desertion ranges between 30\% and 50\%, while in Germany, the rate is between $20 \%$ and 25\%, Switzerland between $7 \%$ and $30 \%$, Finland $10 \%$ and Netherlands between $20 \%$ and $30 \%$;

These results show a common problem, although the causes are different. That is why the research has to be broadened in order to find relationships between educational systems, educational public policies, access to education, development models and the expectations of young people in training. (Vélez, 2004)

Abandonment and the skipping of school have been associated with established risk factors; on the one hand social risk is mentioned and on other hand academic risk. The first category includes aspects such as: race, ethnic group, gender, age, minority language, socio-economic status, family structure, level of education of parents, place of residence, etc. These factors have been used to characterize the risk of students having problems related to school. The greater the number of these factors that affects the student the greater the risk of failure. On the other hand, the academic risk category comprises aspects related to school problems, such as: low grades, low educational expectations, repetition of courses, discipline troubles, etc., such aspects can predict future difficulties at school, such as absenteeism and the skipping of classes, and in fact, abandonment, particularly if these aspects are manifested in a early stage. (González)

It is no coincidence that the rates of abandonment are lower in countries with more selective higher education institutions than in those countries with open systems of higher education, where there are courses with limited intake.

Four types of student desertions can be described: 1) desertion or absolute student abandonment happens when a number of students leave college for academic reasons or any other motive. 2) desertion or relative student abandonment is defined as the relative proportion of students who drop out of college divided by the total number enrolled; 3) absolute academic desertion is defined as the number of students that do not pass to the following academic semester, either because of leaving the University or due to they lost courses and they could not get enough credits required to advance to the next semester, and 4) absolute academic desertion, is the relationship between the number of students that do not pass to the following semester divided by the total amount of students. (Vélez, 2004)

In opinion surveys realized to find out the causes of failure and desertion, most students expressed a lack of vocational guidance, lack of preparative information on the part of high school; as a result, after having chosen the degree course the students feel disappointed due to the fact that the course does not meet with their expectations.

On the other hand, after having applied principals for the opinion survey, they referred to some other aspects that have an influence on failure and desertion in the first semesters of the degree, such as: deficient base knowledge acquired in high school, lack of vocational guidance, methods of selecting students in the entrance examination, family and economic troubles suffered by pupils. The mentioned variables indicated that the heads of school have a significant influence on students' desertion and reprobation $(\mathrm{Cu}, 2005)$.

It is difficult for students at risk of exclusion to solve problems by dealing exclusively with those matters of an organizational nature; not because they lack importance, but the organizational aspect requires sense and meaning when we consider simultaneously questions concerning the curriculum. 
While discussing performance and school desertion, it is very important to take into account the emotional surroundings of the university student as a part of an educational environment, which can influence academic results positively as well as negatively. There is a growing awareness that social and emotional factors play an important role in the academic success of students. The research has shown that students who are more responsible and have positive relationships operate better in academic contexts (Gumora, 2002). Until recently, emotional experiences related to learning and achievements have been neglected in the educational research. However, in the last 10 years, there has been an increase in theoretical and empirical contributions about emotions in education (Gotees, 2008).

It has been suggested that social emotions perform an important role in the collaborative learning. These emotions may be associated with students or groups of students (emotions "I/He" and "I-They"); also they can be shared by a group and directed to another group of students (emotions "We-They"). The research considers that a wide range of social, positive and negative emotions related to these categories can play an important role in the collaborative learning, and in the same way, the emotions have a big impact on students' motivation to take part in tasks of collaborative learning (Perkun, 2005). The evidence suggests that the students' emotions are diverse and much richer in nature than the traditional opinions suggest.

It does not seem to be justifiable to reduce conceptually the emotional life of students with regard to anxiety or to the four emotions: pride, embarrassment, hope and fear, as indicated by the traditional achievement motivation theories. All kinds of human feelings can play a significant role in learning and achievement, including self-emotions and those which are related to tasks, as well as the social and even discrete emotions such as chagrin, which can be important.

In order to reverse the process of school desertion, we must take into account the interests, demands and forms of the social intervention of youngsters. In short, youth culture must be effectively integrated within school culture.

The results shown also suggest that emotions can be fundamental for situational development, including correct development since the embryonic period in order to straighten interest, motivation, will and effort of students. There is convincing evidence regarding the functional importance of the academic emotions of students and their educational and social background. Negative emotions have been used to predict lower levels of recurring social competence. Furthermore, they can be connected to low levels of academic performance. (Rumora, 2002)

It has been found that positive emotions help to develop opinions at the time of enrolling on a degree, and professional aspirations, etc., for instance, if students experience little positive emotions related to mathematics, students are less likely to study a career in this area. Existing research suggests that the positive emotional experiences play an important role in the academic performance and can have a considerable impact on the cognitions, behavior, and ultimate success of students in the academic area. Because of the clear relevance of emotions in the educational process, the background of the positive emotional experiences of students is a major route for more thorough research. Specifically, students experience positive emotions in educational environments that foster positive affective experiences such as pleasure, hope and pride (Gotees 2008). In a specific way, teachers that combine positive emotions with great expectations, have students with better academically oriented goals, as well as better school performance.

Finally, it is clear that the emotions of the students are developed in social contexts. However we do not know how this process can be encouraged, in such a way that pleasure from learning increases and the negative feelings that hinder learning are avoided or changed in order to use them in a positive way. Therefore, while the links between emotions and the processes of learning continue to be analyzed, future research of emotions in the educational context should be realized, as well as providing vital information to parents, educators and administrators as to how schools, instruction in the classroom and social interaction with students can be modified in order to promote the emotional and academic development of students. (Perkun, 2005)

Reversing the processes of school desertion involves firstly taking charge of the interests, demands, and forms of social participation of young people. In short, it involves effectively integrating youth culture into school culture. 


\section{METHODOLOGY}

For this study, a questionnaire with 7 closed questions and one open was prepared, all of which were previously validated. The closed questions had several options in which students should number them from one upwards, according to importance, using their own experience to do so.

The aim of the questionnaire was to investigate, emotional, economic, social, health and family aspects that affect academic performance, temporary or definitive desertion in students of the public accounting school of Puebla State University. The last question was open to give the students the freedom to include any situation that may not have been contemplated in the rating system.

The sample was composed of 416 subjects in a student population of 3748 students who are currently pursuing a Bachelor's degree in the FCPBUAP. 11 groups were chosen, at random, in different academic levels and timetables. Once the rating system was applied, the results were analyzed and the statistical work carried out.

\section{RESULTS}

\section{Graphics And Interpreting}

1. Have You Been Affected By Any Of The Following Personal Or Economic Factors?

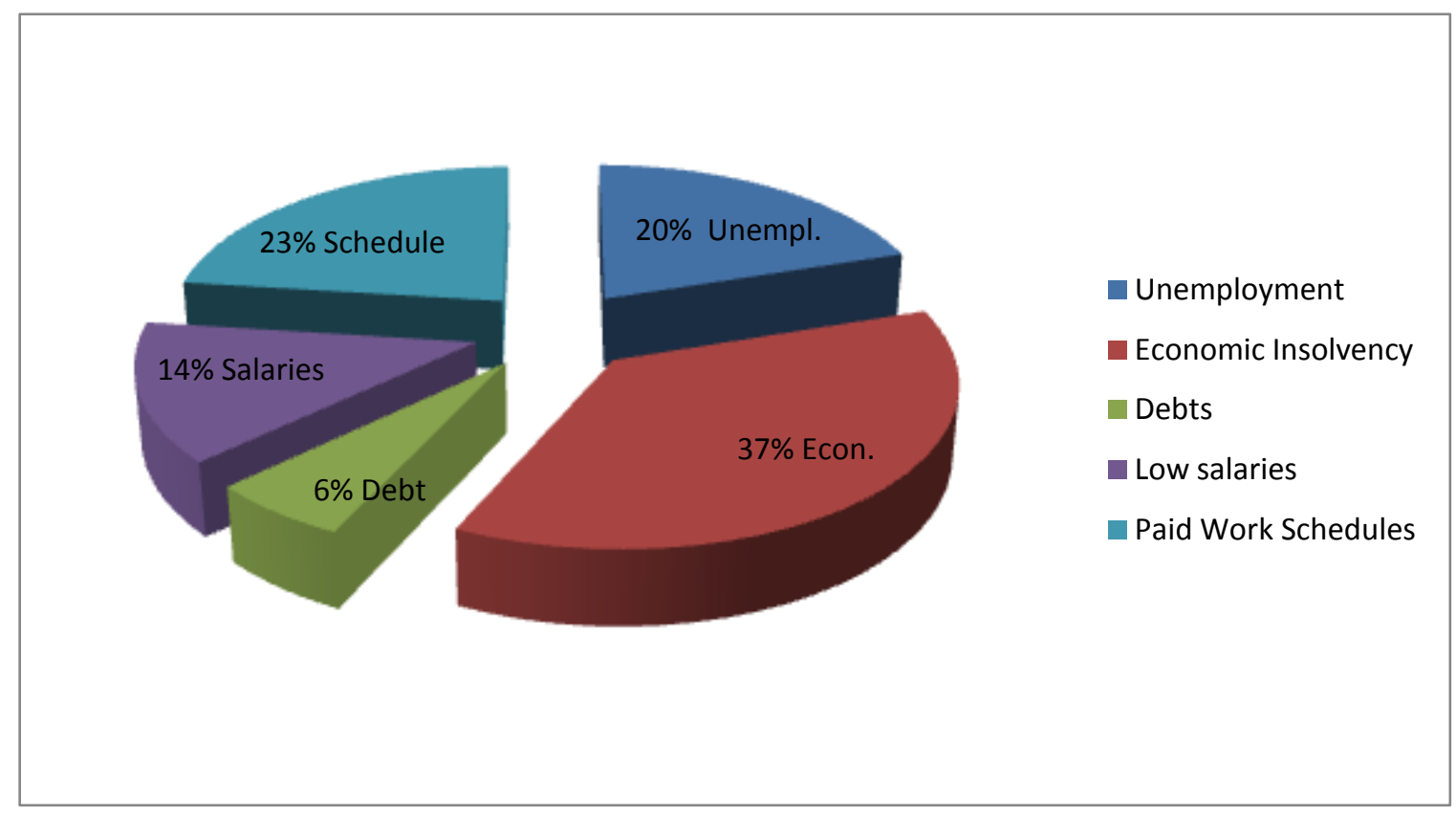

\section{Resource: Own}

In relation to this question, most of the surveyed students reported that economic insolvency is one of the main factors affecting their studies, added to the clashing of their labor schedules with their school timetables; unemployment and low salaries are additional factors which affect their performance and cause academic desertion due to a lack of essential resources to cover their personal expenses

2. Which Of The Following Factors Have Affected Or Will Affect Your Studies? 


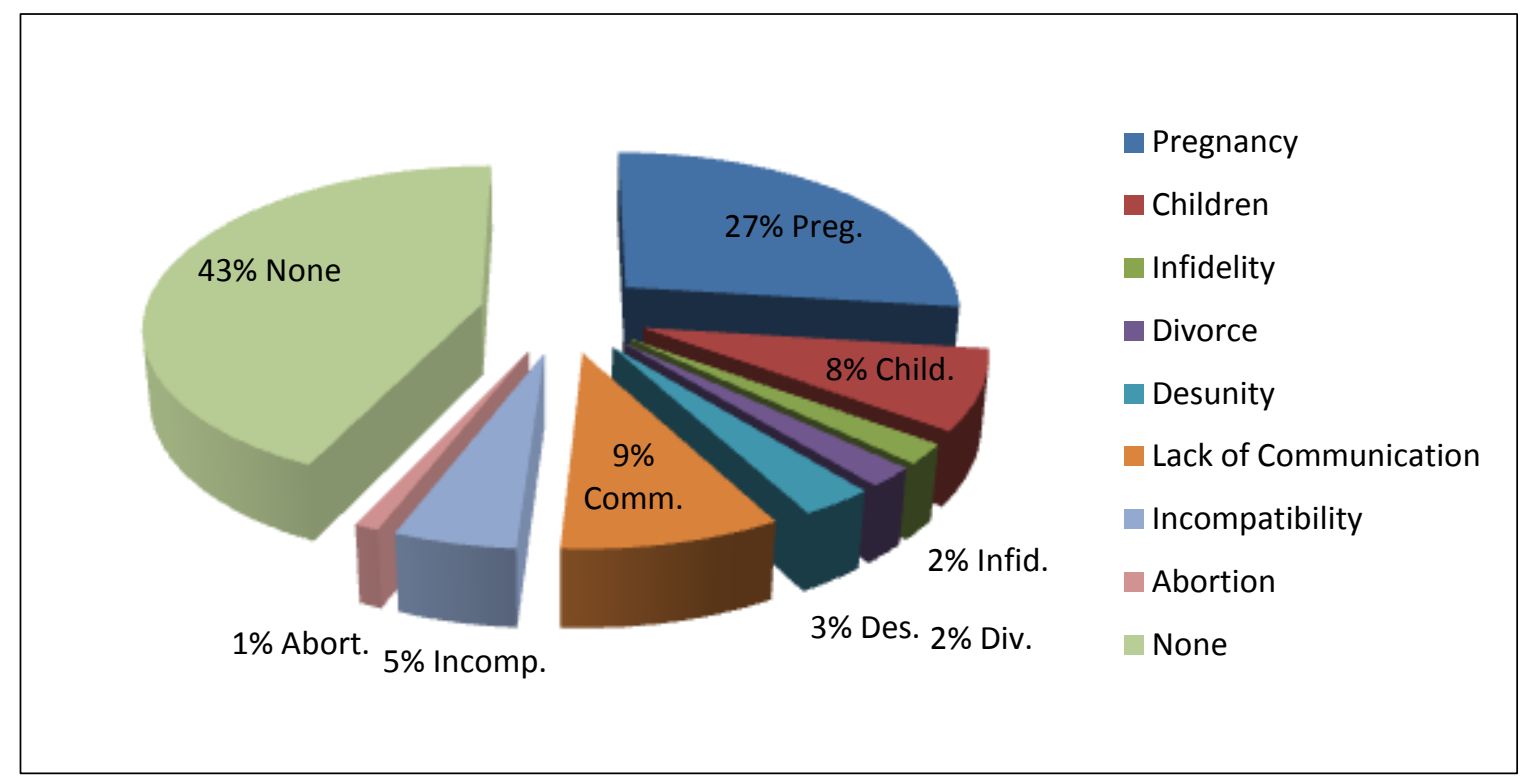

\section{Resource: Own}

In accordance with the results obtained as a consequence of this question, 13 percent of the surveyed persons answered: none of the mentioned factors has affected their performance in their studies, $34 \%$ have been affected by pregnancy, since students think that having a baby ends study plans and prevents the conclusion of a bachelor's degree; 15\% are affected by lack of communication with their relatives; $13 \%$ thought that having children makes it difficult to maintain a good academic achievement; Similarly, incompatibility, disunity, infidelity and divorce are emotional situations which significantly affect students, who become depressed, thus preventing their concentration on their studies, resulting in a low academic performance, in the best cases, if they do not succumb to temporary or definitive desertion. It is important to mention that abortion is not important, so female students prefer to be single mothers than transgress the rules of a conservative society.

3. Which Of The Following Factors Of The Parent- Child Relationship Affect Your Studies?

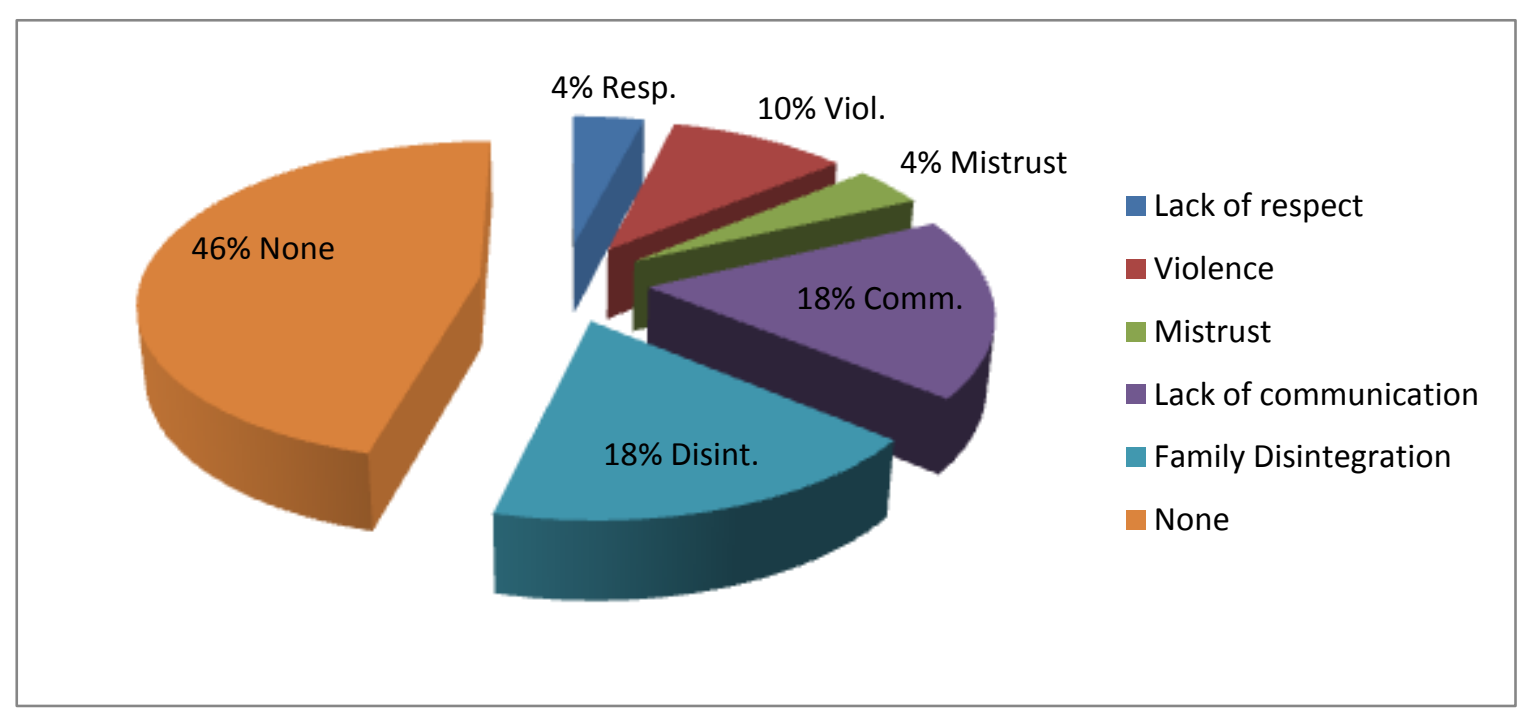




\section{Resource: Own}

Of the 416 respondents, 81 stated that they were not affected by any of these factors. Nevertheless, 130 people mentioned that family disintegration influences their school performance. And the same number of students considered that the lack of communication with their parents forces them to resolve their issues by themselves, and sometimes, under the influence of third parties, preventing them from making the best choice. 41 referred to the fact that domestic violence, either physical or psychological, is an important factor affecting his or her studies. Finally, mistrust and lack of respect also provoke emotional problems that prevent concentration on their studies.

4. Which of the following personal or family factors affect your undergraduate studies?

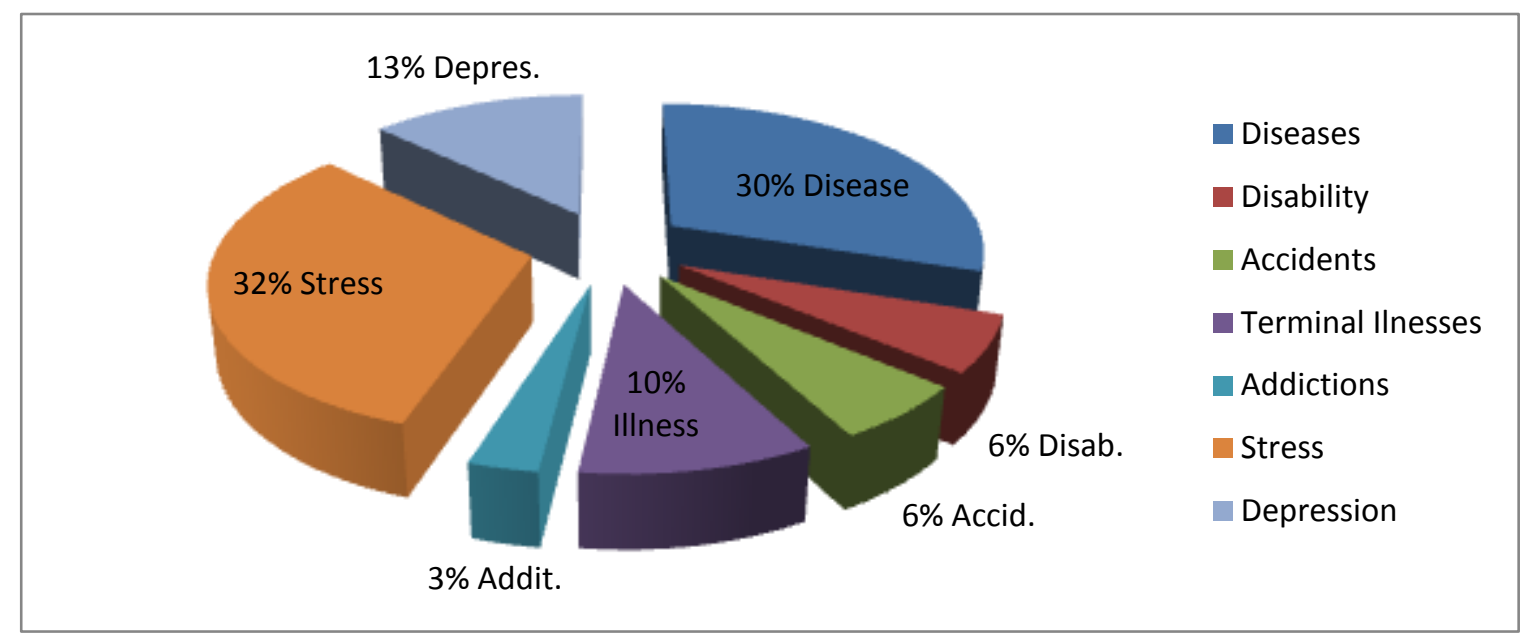

\section{Resource: Own}

The majority of respondents agreed that stress and the disease, in general, are the main factors affecting their performance at the University; in the same way, depression and terminal illness, whether their own or those of family members, are other factors that affect academic performance and school desertion; on the other hand, disability and accidents are also elements that dampen their ability to concentrate on their studies, although to a lesser extent; and finally, addictions represent $3 \%$, which indicates a relatively healthy population.

5. Why did you start at public accounting school?

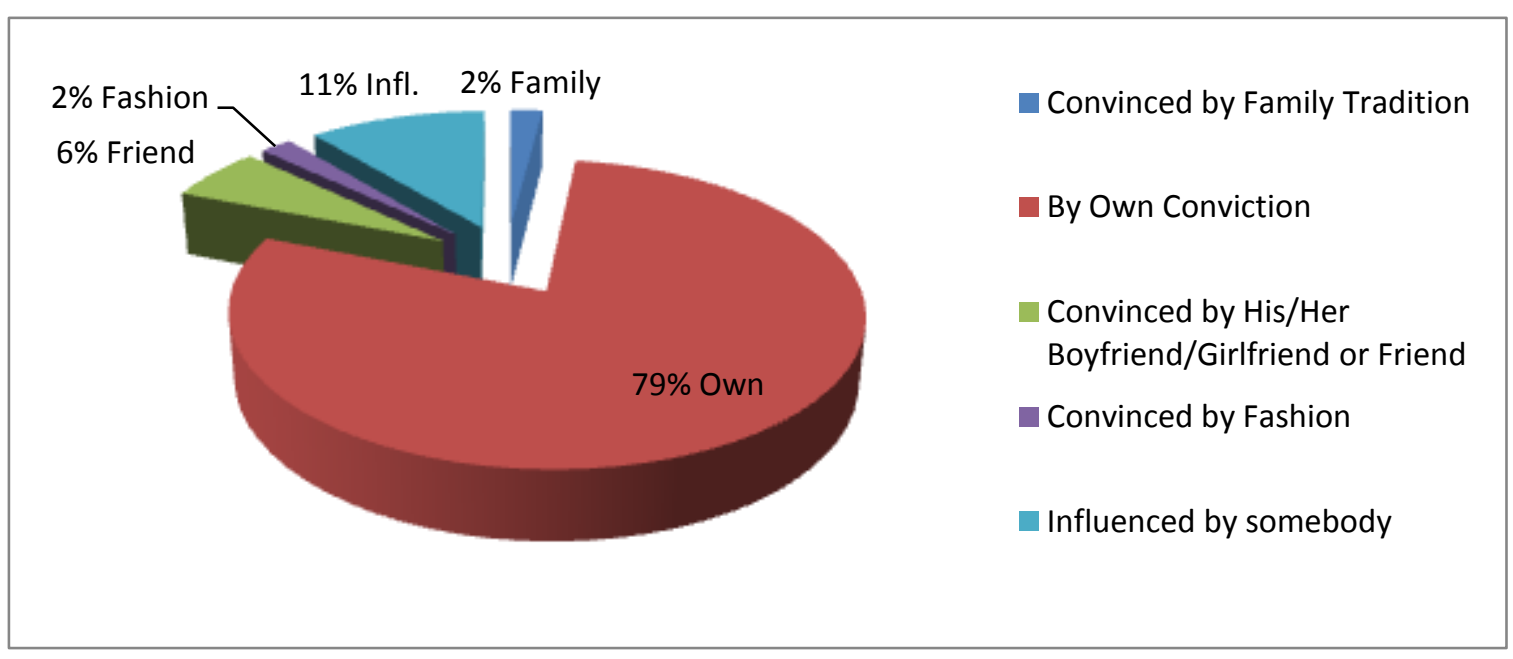




\section{Resource: Own}

The previous graphic shows that $79 \%$ of students chose career by their own conviction, $11 \%$ were influenced by somebody, $6 \%$ were convinced by her/his boyfriend/girlfriend or a friend; $2 \%$ convinced by fashion and $2 \%$ by family tradition.

6. If You Entered Public Accounting School Because Of Any Of The Reasons Mentioned In The Previous Question, How Does That Make You Feel?

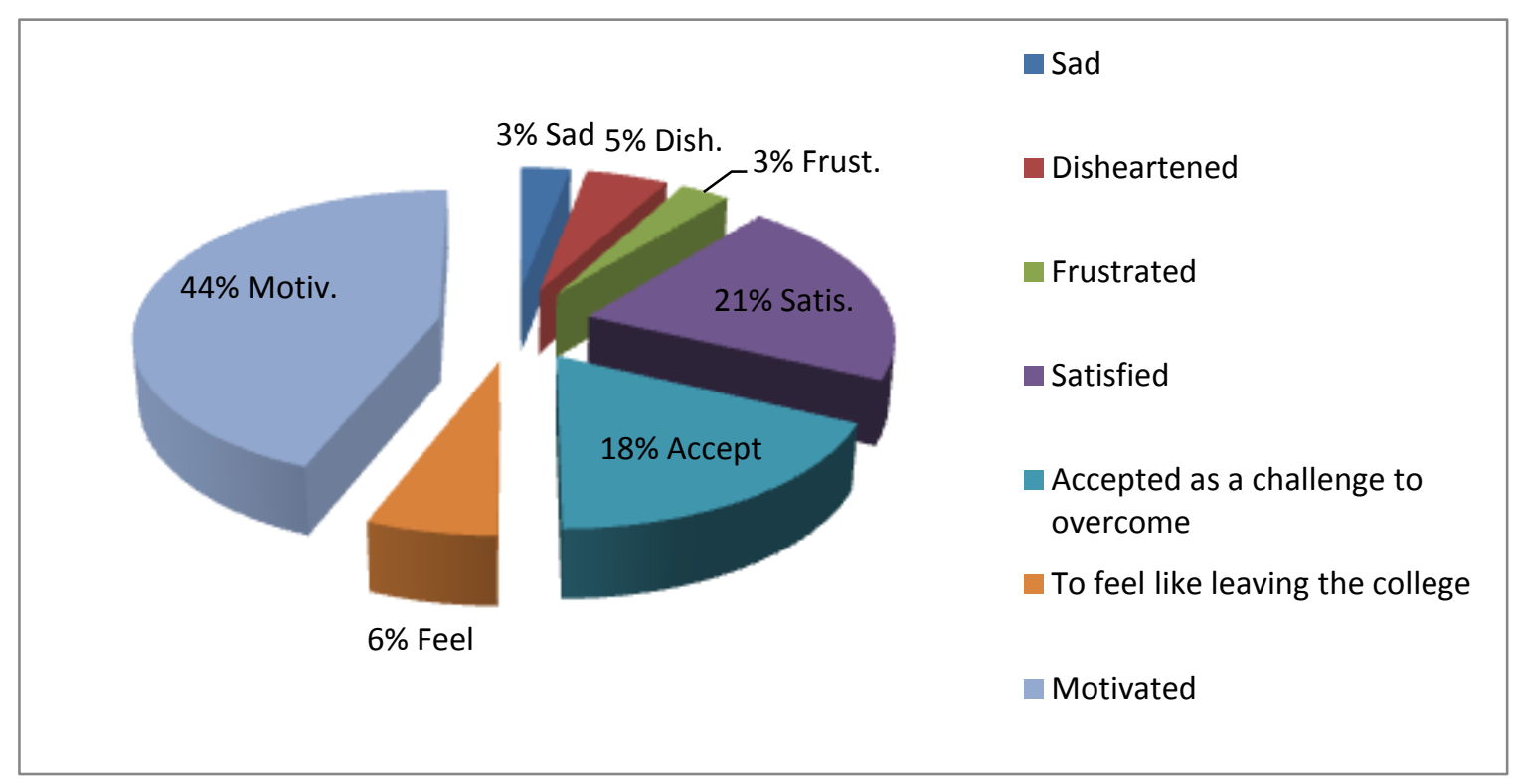

\section{Resource: Own}

You should take into account that in previous question, $79 \%$ of respondents said they had chosen their degree by their own conviction, nevertheless, only $44 \%$ are motivated; $21 \%$ are satisfied with acquired knowledge and $18 \%$ take it as a challenge to overcome. This means that they chose their degree without proper vocational guidance, and of the rest of the students in the survey, who chose by diverse influences, $6 \%$ said they have felt like leaving school; 5\% said they feel disheartened; $3 \%$ are frustrated and 3\% sad.

7. Have you thought about dropping out of school?, why

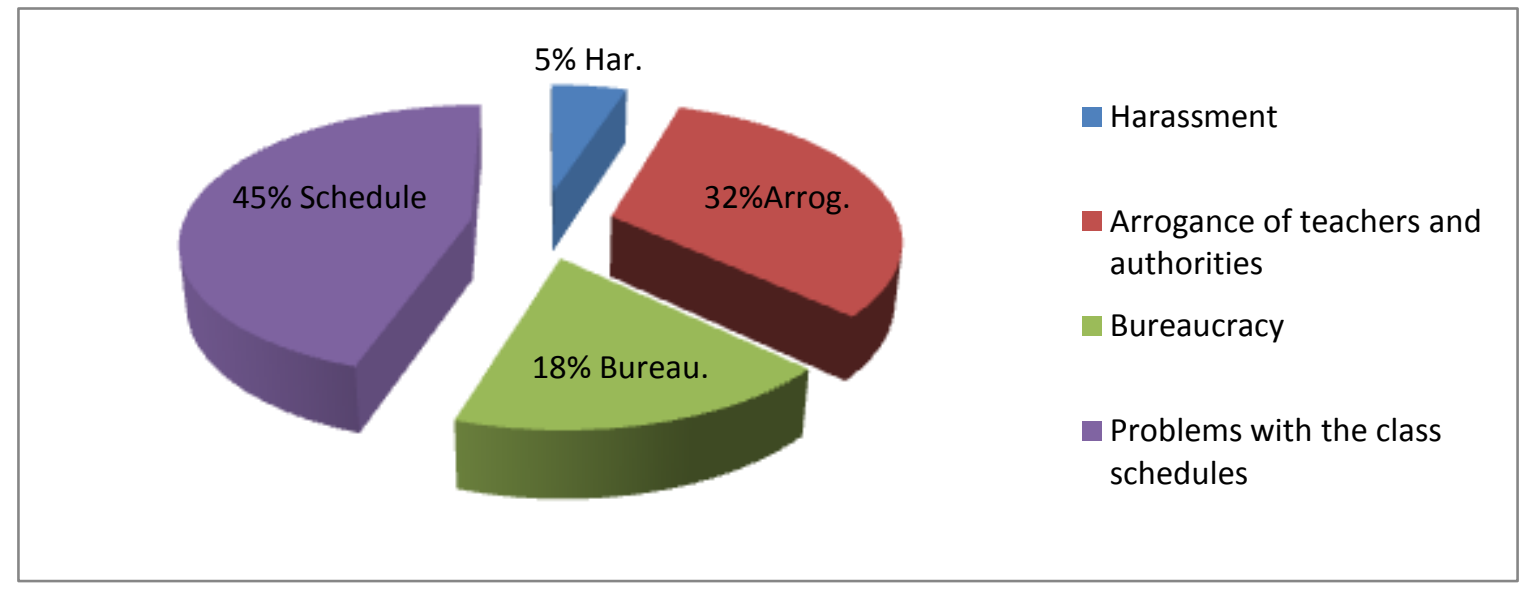




\section{Resource: Own}

According to the results obtained, $45 \%$ of students reported that they have considered leaving College due to problems with the class schedules, 32 per cent due to the arrogance of teachers and authorities, $18 \%$ due to bureaucracy and $5 \%$ for harassment.

8. If there are any factors that affect your staying and the completion of your bachelor's degree, which were not considered in this questionnaire?, please mention them.

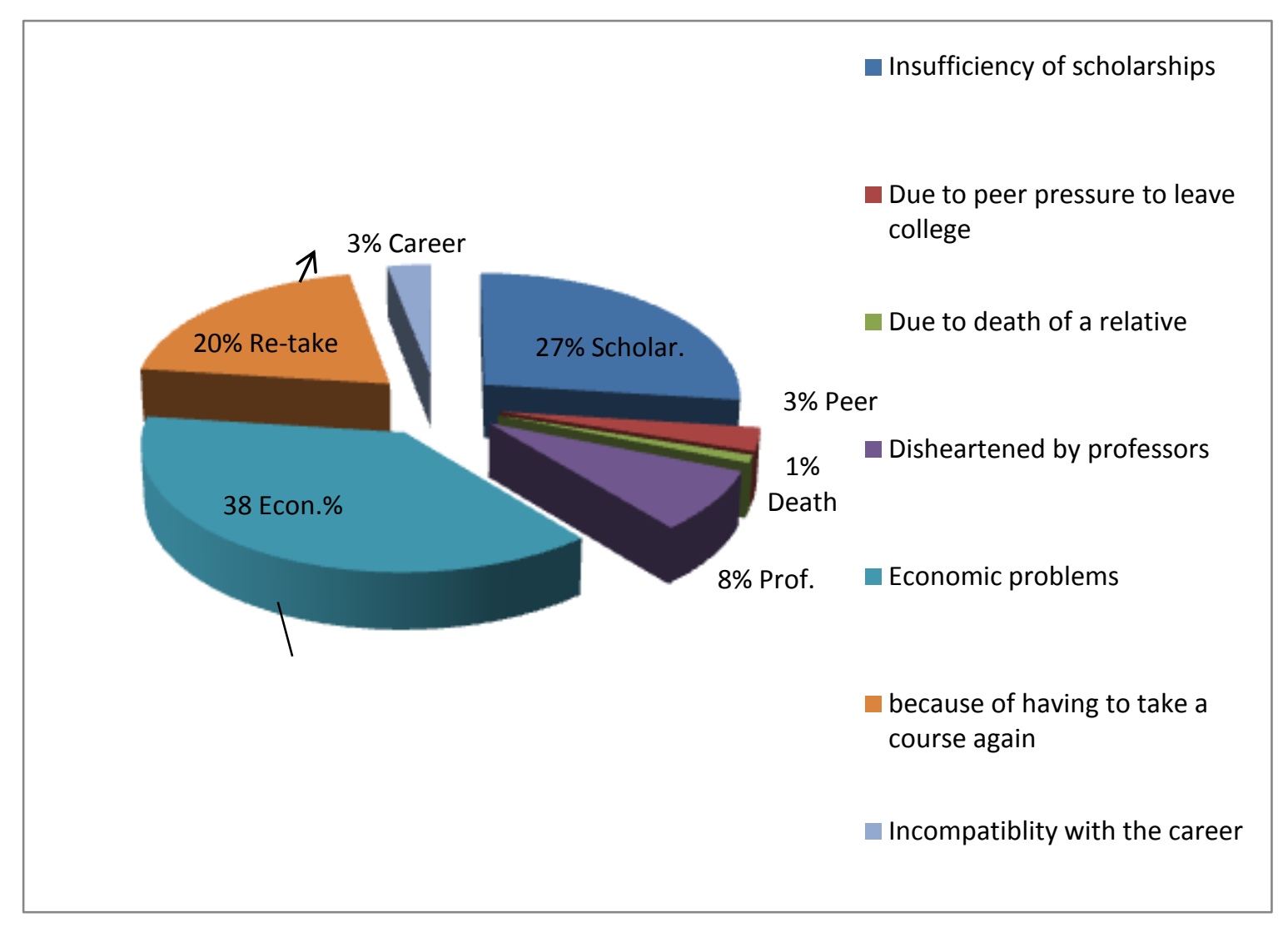

\section{Resource: Own}

$38 \%$ of students reported that they have considered leaving College due to the lack of motivation on the part of their professors; $27 \%$ by insufficiency of scholarships, $20 \%$ because of having to take a course again; $8 \%$ are disheartened on the part of professors, a smaller percentage reported incompatibility with the career, as well as peer pressure to leave college; and finally $1 \%$ of the respondents felt like leaving college as a result of the death of a relative. It should be mentioned that these are factors that students consider account for low academic performance as well as the temporary or definitive desertion of their studies, which were not considered in the rating system.

\section{CONCLUSIONS}

From the results, it was noted that the low academic performance of students is related to economic insolvency that prevents them from concentrating on their studies, as well as in the tasks or jobs that are assigned in class. The students maintain timetables offered by the University that clash with their work schedules, which makes it difficult to organize their time in order to carry out both functions. In the same way, low salaries earned by students or their parents prevent them from satisfying their personal or school needs (books, materials, computers) 
which are essential for their studies. Also accidents and illnesses can provoke important expenditures that affect their precarious economic situation.

Other factors that affect academic performance and school desertion are: pregnancy, depression, family disintegration, stress, distrust, lack of communication, addictions, lack of communication, lack of respect, domestic violence causing that students feel sad, discouraged, frustrated, eager to abandon the college; in addition, many of the students did not choose their career under own conviction, but influenced by someone else, by family tradition or fashion, preventing them from concentrating on the study, giving as a result a poor academic performance, at best, they can temporarily or permanently desert their studies.

In addition, lack of understanding on the part of scholastic authorities dishearten students.

\section{PROPOSALS}

1. You should design and put into practice solution strategies in order to solve the most common and neglected problem during last few decades (pupils' emotions, which arose in the family, social, economic and cultural environment) to promote self-esteem through recognition of personal capabilities. In this way you would support young people in their efforts to conclude their studies, keep them away from bad habits, prevent pregnancies, and vandalism, etc; therefore we propose that self-esteem and motivation be part of the scholastic programs.

2. Taking into account that not all parents know the personal needs of their children (such as: affection, care, communication, confidence in the family environment) it is important to let them know the obstacles they will face, such as: stress, depression, feelings of loneliness, disintegration, and family violence, so as to help them to face, in a better way, their personal and professional problems. Therefore it is suggested that they attend a cycle of conferences, talks, book recommendations, and read journal articles related to the area of education, self-esteem, success, personal improvement, understanding, motivation, self-control, self-conscience, empathy, initiative, adaptability, conviction, capacity development, aptitudes, abilities, skills, management of emotions, communications, values, rules and habits.

3. Other proposal consists of the encouragement of students by professors, so that they are able to develop their skills and can combine knowledge and emotions in order to confront any kind of situations presented in their lifetime.

4. It is very important to promote vocational guidance, since it will impact future professionals, as well as society in general, leaving fashion and imitation aside, at the moment of choosing a career.

5. Another proposal consists of implementing and promoting entrepreneur programs, with the aim that graduates can independently practice their profession, assuring income for themselves and at the same time creating sources of work.

\section{AUTHOR INFORMATION}

Emma Rosa Cruz Sosa Profesora Investigadora de la Unidad de Planeación, Investigación y Evaluación, así como miembro del Centro de Investigación, de la Facultad de Contaduría Pública. Benemérita Universidad Autónoma de Puebla. México. Email: emmarc2001@ yahoo.com.mx

Laura Gatica Barrientos Profesora Investigadora de la Unidad de Planeación, Investigación y Evaluación, así como miembro del Centro de Investigación, de la Facultad de Contaduría Pública. Benemérita Universidad Autónoma de Puebla. México. Email: ekalg@ hotmail.com

Patricia Eugenia Garcia Castro Profesora Investigadora de la Unidad de Planeación, Investigación y Evaluación, así como miembro del Centro de Investigación, de la Facultad de Contaduría Pública. Benemérita Universidad Autónoma de Puebla. México. Email: patricia.garcia@fconta.buap.mx

Jesús Hernández García Profesor Investigador de la Unidad de Planeación, Investigación y Evaluación, así como miembro del Centro de Investigación y del departamento de Inglés de la Facultad de Contaduría Pública de la Benemérita Universidad Autónoma de Puebla. México. Email: master7@live.com.mx 


\section{BIBLIOGRAPHY}

1. Ramírez M, Caballero J, et al. The social networks of academic performance in a student context of poverty in Mexico. Social Networks 2004; 26:175-188.

2. De la Fuente J, Cardelle M. Research on action-emotion style and study habits: Effects of individual differences on learning and academic performance of undergraduate students. Learning and Individual Differences 2009; 19:567-576.

3. Edel R. El rendimiento académico: Concepto, investigación y desarrollo. Revista Electrónica Iberoamericana sobre Calidad, Eficacia y Cambio en Educación 2003; 1(2):1-15.

4. Byrne M, Flood B. Examining the relationships among background variables and academic performance of first year accounting students at an Irish University. J. of Acc. Ed. 2008; 26:202-212.

5. Vélez A, López D. Estrategias para vencer la deserción universitaria. Educación y Educadores 2004; 7:177-203.

6. González M. Absentismo y abandono escolar: Una situación singular de la exclusión educativa. Revista Electrónica Iberoamericana sobre Calidad, Eficacia y Cambio en Educación 2006; 4(1):1-15 .

7. Cu G. El impacto de la escuela de procedencia del nivel medio superior en el desempeño de los alumnos en el nivel universitario. Revista Electrónica Iberoamericana sobre Calidad, Eficacia y Cambio en Educación 2005; 3(1):764-769.

8. González M. El absentismo y el abandono: una forma de exclusión escolar. Profesorado. Revista de Currículum y Formación de Profesorado 2005; 9(1):1-12.

9. Gumora G, Arsenio W. Emotionality, Emotion Regulation, and School Performance in Middle School Children. Journal of School Psychology 2002; 40(5):395-413.

10. Goetz T, Frenzel A, et al. Antecedents of academic emotions: Testing the internal/external frame of reference model for academic enjoyment. Contemporary Educational Psychology 2008; 33:9-33.

11. Pekrun R. Progress and open problems in educational emotion research. Learning and Instruction 2005; 15:497-506.

12. Goicovic I. Educación, deserción escolar e integración laboral juvenil. Última Década 2002; 16:11-53. 
NOTES 